\title{
COMPARISON THROUGH AGE-SEX COMPOSITION OF THE DISTRICTS OF WEST BENGAL BASED ON CENSUS 2011 DATA
}

\author{
Tushar Kanti Ghara \\ Joint Director of Public Instruction, Higher Education, Govt. of West Bengal, $8^{\text {th }}$ Floor, Bikash Bhavan, \\ Salt Lake City, Kolkata 700091
}

DOI: 10.46609/IJSSER.2020.v05i08.006 URL:https://doi.org/10.46609/IJSSER.2020.v05i08.006

\begin{abstract}
Age-sex composition of population speaks many unexplained features of a population. The districts of West Bengal are mostly non-homogeneous due to these age-sex composition of the population. The single age population of census 2011 data (Table-C13 of Census 2011 digital Library) has been considered. The different age groups combinations have been considered to bring the similarity of social structure. Population pyramids and specific dependency ratio have been calculated.
\end{abstract}

Keywords : Population Pyramid, Specific Dependency Ratio, Age Group, Social well-being

\section{INTRODUCTION}

India, with over 1.21 billion population (2011 census), contains more than one-sixth of the world's population is projected to be the world's most populous country by 2025 . India's growth rate for 1990 - 2011 is $40.2 \%$ whereas for the world it is $30.0 \%$ and China numbers at a low $17.1 \%$. West Bengal ranks fourth (7.55\%) among the Indian states in terms of population. Agesex structure is the diagrammatic representation of population of a region, systematically arranged in age groups/cohorts along the vertical axis and sex wise along the horizontal axis. The analysis is critical to any spatial unit because inherently it bears the signature of its history and is instrumental in defining and predicting the social-cultural-economic geography of the region. Age and Sex are two important demographic components. Births, deaths and movement of population are inherently inter-dependent and change in one may influence the other. Reproduction, physical ability, circumstances of employment, mental attitude is influenced by age. Birth rates are higher indicates higher proportion of individuals is higher in early ages as compared to the old and visa-versa. Factors like age of schooling, enrolment in voter list, age of marriage etc are determined by age. Age and sex are important to indicate individual's social status, working status, appearance, income, home ownership, occupation, etc. In 2020, 
projections indicate more than one billion older persons $(60+)$ in the world $-23.4 \%$ will be in China and 7.4\% in the US. In 2020, projections indicate almost 149 million oldest-old people $(80+)-19.4 \%$ in China and $8.9 \%$ in the US. The study will include the differences in different factor over three census years (Mandal, 2020). There is a noticeable change in the shape of age sex pyramid of WB from 1961 - 2011 (Fig.1). The broad-based pyramid with very high proportion of child population and considerably small proportion of working population has eventually transformed into a balloon shaped pyramid with moderate child population and a huge proportion of working population. The notch noticed in 1961 pyramid is perhaps the result of partition in 1947. The shrinking of the base starts mainly from 1971 but the increase of percentage of the working population is noticeable from 1991. In 2001, the child population for both the sex came down to less than $10 \%$ of the total. The 2011 pyramid is an example of an almost developed nation that is approaching towards maturity that is a cylindrical shaped pyramid (Saha and Sarkar, 2015).

Figure-1 : Age-Sex Pyramid of West Bengal 1961 to 2011

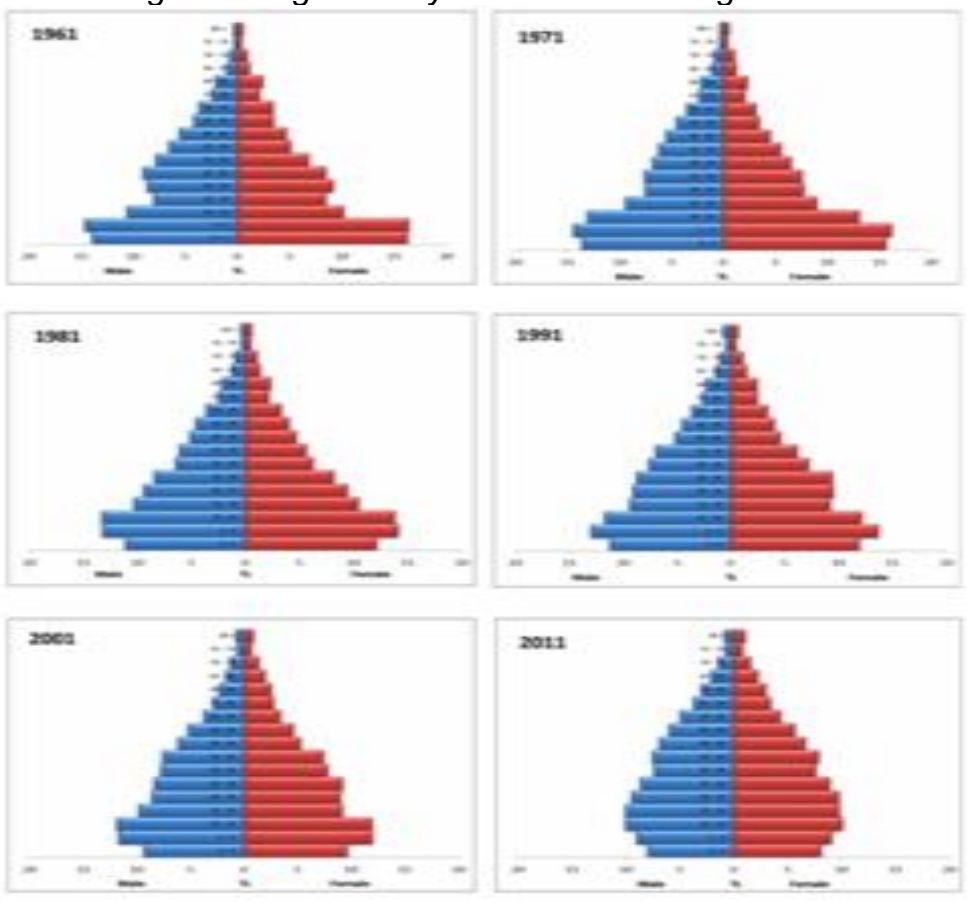

Dependency ratio means the ratio of working age people face a burden in supporting the aging population on overall economy and healthcare. The inverse of the dependency ratio, the inverse dependency ratio can be interpreted as how many independent workers have to provide for one dependent person (pension \& expenditure on children including health). The ultimate utility of dependency ratios as a measure of local well-being remains unclear. The ratio of dependent 


\section{International Journal of Social Science and Economic Research}

ISSN: $2455-8834$

Volume:05, Issue:08 "August 2020"

population (0 - 14 and > 59) and the working population (15 - 59). It is important for planning and formulating government policies. India had a death rate of around 90\% in 1961 which increased slightly in 1971, decreased at a stable rate for the next three decades and then had a step fall to $65 \%$ in 2011 (Fig.2). Male and female showed similar pattern ad there were no disparity between male and female death rate. WB male started with a death rate less than $80 \%$ which swelled to over 85\% in 1971, then decreased in 1991 drastically and since then it decreased at a stable rate to reach beyond 55\%. WB females had a high DR around $95 \%$ that hiked to $105 \%$ and in 1971 and slipped at an increasing rate in 1981, after that there has been a rapid decline in WB female DR and in 2011 it is less than $60 \%$.

Figure-2 showing Dependency Rate of West Bengal 1961 to 2011

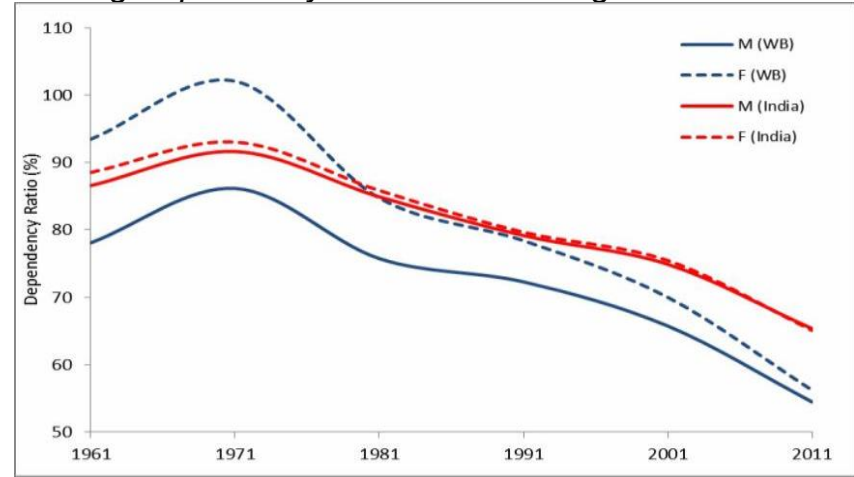

Both the sexes have different biological, social and cultural functions and role (Pressat Roland, 1978). Both the sexes can migrate to any ages, though migration is particularly high among men of early working age (15-29) and women around the age of marriage (Mukherjee, 1976). The working age group (15-59) is biologically the most reproductive, economically the most productive and demographically the most mobile (Trewartha, 1969). Factors like age of schooling, enrolment of name in voter"s list, marriage etc. are generally determined by age. Sex and age are also very important because they are the "visible indisputable and convenient indicators of social status (Thomlinson, 1965). The young age group is economically unproductive and solely dependent upon the adult age group. The proportion of population in the young age group (below 15 years) is determined by the stage of demographic transition through which it is passing where larger proportion indicates first and second stage of transition (Chandna, 2005). An effort to create "adjusted" dependency measurements that better account for non-age related factors, age-disaggregation approach by accounting for social and economic community characteristics that may interact with age components. This adjustment process relies of a series of weights applied to the unadjusted measure of the dependency ratio, and allows us to reflect on whether the population of a given metro area has actual greater or lesser 'dependency', net of the social and economic characteristics that make communities what they are. These 


\section{International Journal of Social Science and Economic Research}

ISSN: $2455-8834$

Volume:05, Issue:08 "August 2020"

additional factors include measures of poverty, family structure, physical disability, and educational attainment. A series of social and economic indicators like the percentages of children with the following characteristics: Living in poverty Living with a physical disability Living in a household where a primary householder has less than a high-school degree living in a household without both parents present. After determining these percentages, we create z-score values by testing each estimate against the appropriate national average (child poverty in Billings, Montana vs. child poverty nationally, etc.). The multiplier adjustments based on the size and nature of the $\mathrm{z}$-score values may reflect true dependency ratio. An alternative to the dependency ratio may be the LFPR (Labour Force Participation Ratio). The social factors are never being reflected by LFPR and Dependency Ratio. An approach is being tried to measure specific dependency ratio in this communication. This communication aims also to show disparities in the population structure age and sex-wise to look into the future of the characteristics of population. It aims to have ideas about the population in education, work sphere and old-age influences for the future. The population has been divided into 9 age groups like - 0-5(pre-school)(A), 6-9(primary school)(B), 10-15(high school)(C), 16-17(higher secondary)(D), 18-23(higher education)(E), 24-44(active young work force)(F), 45-59(older work force)(G), 60-80(pension/old-age)(H) and 81-w(pension/high risk/older age)(I).

\section{DATA}

The census population table $\mathrm{C}-13$ has been considered here as basic data source. Only West Bengal population for all ages ( 0 to maximum age $(\mathrm{w})$ ) have been considered which has been divided into nine age-groups - 0-5(pre-school), 6-9(primary school), 10-15(high school), 1617(higher secondary), 18-23(higher education), 24-44(active young work force), 45-59(older work force), 60-80(pension/old-age) and 81-w(pension/high risk/older age). The same division has been done for all the districts - Bankura(BAN), Birbhum(BIR), Burdwan(BRD), Dakshin Dinajpur(DD), Darjeeling(DAR), Howrah(HWH), Hooghly(HGH), Jalpaiguri(JAL), Coochbehar(CB), Kolkata(KOL), Malda(MAL), Murshidabad(MUR), Nadia(NAD), North 24 Parganas(N24), Midnapur West(MIDW), Midnapur East(MIDE), Purulia(PUR), South 24 Parganas(S24) and Uttar Dinajpur(UD). Further total population for each age group and district has been divided into Male and Female (Table-1). 


\section{International Journal of Social Science and Economic Research}

ISSN: 2455-8834

Volume:05, Issue:08 "August 2020"

Table-1 showing Districtwise-Age Groupwise Male-Female Total Population of Census 2011

\begin{tabular}{|c|c|c|c|c|c|c|c|c|c|c|c|}
\hline & & District & & & & & & & & & \\
\hline Gender & Age $\mathrm{Gr}$ & BAN & BRD & BIR & $\mathrm{DD}$ & DAR & $\mathrm{HWH}$ & $\mathrm{HGH}$ & $\mathrm{JAL}$ & $\mathrm{CB}$ & $\mathrm{KOL}$ \\
\hline Female & $0-5$ & 12482 & 25373 & 7092 & 5112 & 5742 & 19998 & 25493 & 11129 & 9489 & 27060 \\
\hline Female & $6-9$ & 167006 & 293310 & 127015 & 61819 & 61380 & 191742 & 247958 & 118096 & 98315 & 226098 \\
\hline Female & $10-15$ & 246324 & 532753 & 229854 & 110601 & 121127 & 319337 & 410839 & 250818 & 182017 & 368825 \\
\hline Female & $16-17$ & 572857 & 1279938 & 544829 & 265610 & 317518 & 802713 & 943600 & 604965 & 431457 & 768201 \\
\hline Female & $18-23$ & 195153 & 459027 & 206190 & 97083 & 113463 & 291235 & 312493 & 251933 & 170106 & 232720 \\
\hline Female & $24-44$ & 56035 & 133108 & 57712 & 29671 & 35500 & 86716 & 92212 & 78946 & 52792 & 65585 \\
\hline Female & $45-59$ & 209236 & 426125 & 218293 & 109006 & 110776 & 261338 & 285742 & 240701 & 176304 & 194806 \\
\hline Female & $60-80$ & 124932 & 250262 & 131716 & 61269 & 63730 & 154255 & 161995 & 139501 & 102273 & 108650 \\
\hline Female & 81- & 173765 & 346276 & 187775 & 78169 & 79245 & 219047 & 222502 & 192710 & 143775 & 138203 \\
\hline Male & $0-5$ & 9703 & 21442 & 6007 & 4532 & 6147 & 17170 & 20238 & 11310 & 8979 & 26113 \\
\hline Male & $6-9$ & 144635 & 285566 & 116760 & 62518 & 68071 & 198225 & 248475 & 126207 & 99479 & 249883 \\
\hline Male & $10-15$ & 272767 & 616454 & 255623 & 126507 & 132364 & 380331 & 476174 & 288842 & 210317 & 437051 \\
\hline Male & $16-17$ & 594634 & 1337280 & 561336 & 266992 & 313610 & 852301 & 960643 & 621531 & 446586 & 828498 \\
\hline Male & $18-23$ & 210177 & 474064 & 213442 & 100900 & 112372 & 293532 & 309200 & 254565 & 182274 & 251441 \\
\hline Male & $24-44$ & 70745 & 151464 & 72108 & 35398 & 37753 & 92268 & 99779 & 83826 & 60202 & 72283 \\
\hline Male & $45-59$ & 222033 & 449749 & 231642 & 114041 & 115528 & 273836 & 296353 & 248012 & 183240 & 213528 \\
\hline Male & $60-80$ & 128935 & 261620 & 137262 & 63995 & 67152 & 162329 & 168055 & 146062 & 107493 & 116511 \\
\hline Male & $81-$ & 183514 & 364065 & 195521 & 81465 & 83010 & 227199 & 233765 & 201469 & 151629 & 148016 \\
\hline
\end{tabular}

\begin{tabular}{|l|l|r|r|r|r|r|r|r|r|r|}
\hline & & District & & & & & & & & \\
\hline Gender & Age Gr & MAL & MUR & NAD & N24 & MIDW & MIDE & PUR & \multicolumn{1}{|c|}{ S24 } & UD \\
\hline Female & $0-5$ & 9507 & 20017 & 24605 & 55609 & 21722 & 20170 & 7323 & 32453 & 6564 \\
\hline Female & $6-9$ & 117809 & 239721 & 226193 & 432868 & 238713 & 197001 & 125518 & 288524 & 85042 \\
\hline Female & $10-15$ & 212113 & 391498 & 349570 & 727901 & 387900 & 317501 & 187283 & 480576 & 157065 \\
\hline Female & $16-17$ & 559188 & 1008608 & 840573 & $2 \mathrm{E}+06$ & 963675 & 805530 & 437228 & $1 \mathrm{E}+06$ & 409337 \\
\hline Female & $18-23$ & 237721 & 453459 & 308965 & 593084 & 351305 & 316163 & 154542 & 523444 & 162078 \\
\hline Female & $24-44$ & 71406 & 137560 & 88786 & 167292 & 100011 & 89653 & 46606 & 150327 & 55445 \\
\hline Female & $45-59$ & 292678 & 494897 & 289482 & 515582 & 345339 & 297136 & 184026 & 494673 & 229806 \\
\hline Female & $60-80$ & 185138 & 303477 & 164672 & 300512 & 205736 & 176934 & 118887 & 308955 & 151166 \\
\hline Female & $81-$ & 250595 & 425026 & 219980 & 398643 & 286289 & 244779 & 170256 & 430168 & 199064 \\
\hline Male & $0-5$ & 8848 & 15573 & 18765 & 50697 & 19981 & 20841 & 6894 & 28063 & 6449 \\
\hline Male & $6-9$ & 118450 & 224655 & 216399 & 454401 & 226904 & 204008 & 115207 & 292883 & 90836 \\
\hline Male & $10-15$ & 244486 & 444236 & 412769 & 839196 & 445917 & 365809 & 200300 & 548116 & 181088 \\
\hline Male & $16-17$ & 584045 & 1052688 & 879515 & $2 \mathrm{E}+06$ & 968477 & 853108 & 452435 & $1 \mathrm{E}+06$ & 422910 \\
\hline Male & $18-23$ & 246046 & 462071 & 319043 & 586432 & 349221 & 324597 & 165787 & 509019 & 177568 \\
\hline Male & $24-44$ & 85651 & 158922 & 102118 & 180902 & 116418 & 104775 & 58069 & 163833 & 63407 \\
\hline Male & $45-59$ & 306976 & 514276 & 304462 & 542811 & 359908 & 312163 & 193616 & 515524 & 239523 \\
\hline Male & $60-80$ & 193738 & 313221 & 170304 & 314179 & 213700 & 184289 & 124671 & 320624 & 159801 \\
\hline Male & $81-$ & 262014 & 439666 & 229030 & 417214 & 297184 & 258488 & 178351 & 446186 & 208898 \\
\hline
\end{tabular}


International Journal of Social Science and Economic Research

ISSN: 2455-8834

Volume:05, Issue:08 "August 2020"

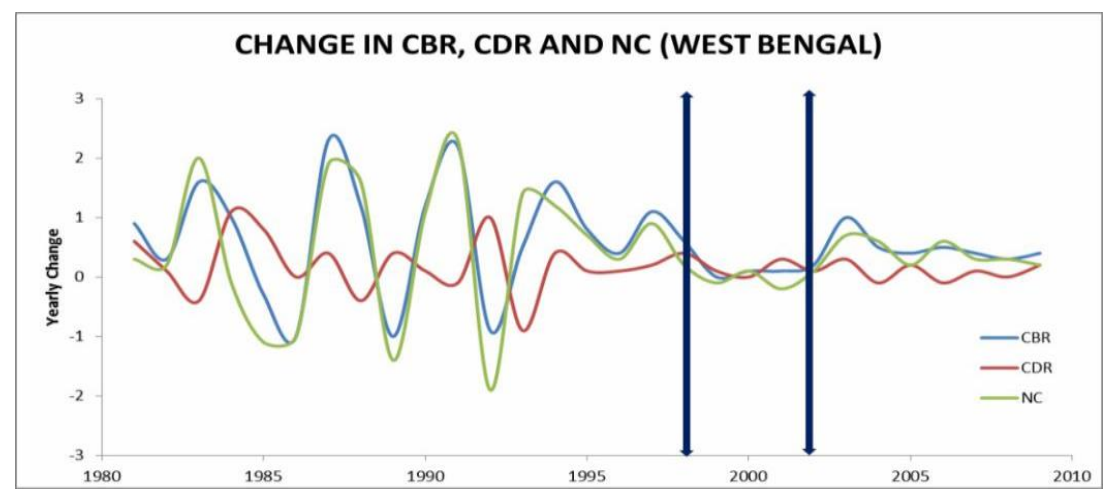

Figure-3 showing Population Pyramids for each districts of West Bengal

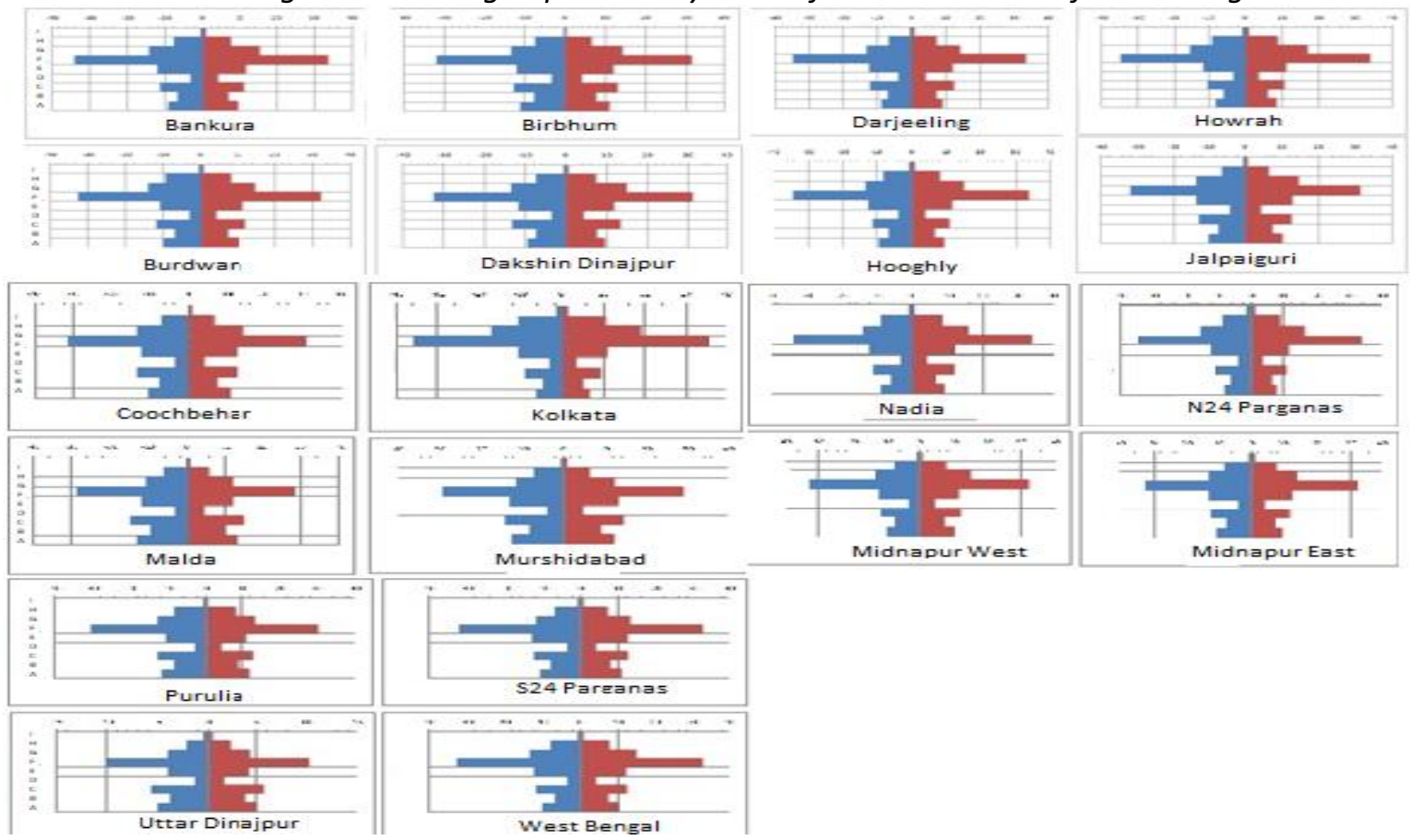

Each of the pyramids are in the shape of a 'kalshi'. The 'Kalshi'-shaped pyramids have the modes in the age group of 16-17 and next in the age group 45-59 and 18-23. The clubbing in the age group 24-44 are varying from districts to districts. These are due to in search of 'Jobs' and people are moving away from home and staying outside for long period. It is mostly in the districts like Dinajpur (Dakshin \& Uttar), Midnapur (East \& West), Malda, Bankura, Darjeeling, Howrah and Coochbehar. These people are at home after attending age 60 or even 50.

The age specific dependency ratio is the population in a specific age group to the all previous age group population or complementary to it. It will measure the proportion of population catered or 


\section{International Journal of Social Science and Economic Research}

ISSN: 2455-8834

Volume:05, Issue:08 "August 2020"

supplemented by previous/all previous populations. It is in other sense the stochastic ratio. Larger the value better is the supplement.

\begin{tabular}{|c|c|c|c|c|c|c|c|c|c|c|c|c|c|c|c|c|c|c|c|}
\hline \multirow[b]{2}{*}{ Age Gr } & \multicolumn{2}{|c|}{ District } & \multirow[b]{2}{*}{$\mathrm{BIR}$} & \multirow[b]{2}{*}{ DD } & \multirow[b]{2}{*}{ DAR } & \multirow[b]{2}{*}{$\mathrm{HWH}$} & \multirow[b]{2}{*}{$\mathrm{HGH}$} & \multirow[b]{2}{*}{ JAL } & \multirow[b]{2}{*}{$\mathrm{CB}$} & \multirow[b]{2}{*}{$\mathrm{KOL}$} & \multirow[b]{2}{*}{ MAL } & \multirow[b]{2}{*}{ MUR } & \multirow[b]{2}{*}{ NAD } & \multirow[b]{2}{*}{ N2 } & \multirow[b]{2}{*}{ MIDW } & \multirow[b]{2}{*}{ MIDE } & \multirow[b]{2}{*}{ PUR } & \multirow[b]{2}{*}{ S24 } & \multirow[b]{2}{*}{ UD } \\
\hline & BAN & $\mathrm{BRD}$ & & & & & & & & & & & & & & & & & \\
\hline $0-5$ & & & & & & & & & & & & & & & & & & & \\
\hline $6-9$ & 2.0 & 2.0 & 1.9 & 2.0 & 1.8 & 1.8 & 2.2 & 2.0 & 1.7 & 1.9 & 1.8 & 1.7 & 1.8 & 1.8 & 1.7 & 1.6 & 1.8 & 1.9 & 1.8 \\
\hline $10-15$ & 2.3 & 2.3 & 2.2 & 2.5 & 2.4 & 2.1 & 2.3 & 2.2 & 2.0 & 2.5 & 2.5 & 2.3 & 2.2 & 2.3 & 2.4 & 2.3 & 2.5 & 2.5 & 2.3 \\
\hline $16-17$ & 0.4 & 0.4 & 0.4 & 0.4 & 0.4 & 0.3 & 0.4 & 0.4 & 0.3 & 0.4 & 0.4 & 0.4 & 0.3 & 0.4 & 0.4 & 0.4 & 0.4 & 0.4 & 0.4 \\
\hline $18-23$ & 0.3 & 0.3 & 0.3 & 0.3 & 0.3 & 0.3 & 0.3 & 0.3 & 0.3 & 0.3 & 0.3 & 0.3 & 0.3 & 0.3 & 0.3 & 0.3 & 0.3 & 0.3 & 0.3 \\
\hline 24-44 & 3.1 & 3.5 & 3.4 & 3.1 & 3.0 & 3.0 & 3.0 & 3.2 & 3.0 & 3.8 & 3.4 & 3.1 & 3.0 & 3.3 & 3.1 & 3.6 & 3.2 & 3.9 & 3.2 \\
\hline $45-59$ & 0.6 & 0.6 & 0.6 & 0.6 & 0.6 & 0.6 & 0.6 & 0.6 & 0.6 & 0.6 & 0.6 & 0.6 & 0.6 & 0.6 & 0.6 & 0.6 & 0.6 & 0.7 & 0.6 \\
\hline $60-80$ & 1.4 & 1.4 & 1.3 & 1.2 & 1.4 & 1.4 & 1.4 & 1.4 & 1.3 & 1.4 & 1.4 & 1.3 & 1.3 & 1.4 & 1.4 & 1.4 & 1.4 & 1.3 & 1.4 \\
\hline 81- & 0.0 & 0.0 & 0.0 & 0.0 & 0.0 & 0.0 & 0.0 & 0.0 & 0.1 & 0.0 & 0.0 & 0.0 & 0.1 & 0.0 & 0.0 & 0.0 & 0.0 & 0.0 & 0.0 \\
\hline
\end{tabular}

\section{REMARKS}

The usual way to compare age-sex comparision of a population are population pyramids and dependency ratio. Here districts of West Bengal have been compared by population pyramids and dependency ratio. It is interesting to note that usual age distribution of population has not been considered and that deviates the picture from pyramids to 'kalshi'. The dependency ratio has also been considered more specifically to bring the idea of social dependency not only economically and healthcare facilities but in other areas of social well-being and maintenance of the age-sex composition. The specific dependency ratio indicates the capacity of sustaining the structure of age-sex from lower or feeder age-group to the next age-group. The age and sex compositions for all the districts are more or less similar. The clubbing in the age group 24-44 are varying from districts to districts. It may be due to in search of 'Jobs' and people are moving away from home and staying outside for long period. It is mostly in the districts like Dinajpur (Dakshin \& Uttar), Midnapur (East \& West), Malda, Bankura, Darjeeling, Howrah and Coochbehar. These people are at home after attending age 60 or even 50 . The same are also being explained by specific dependency ratios. The further derivations may be done on each age data analysis.

ACKNOWLEDGEMENT: I acknowledge Prof Ashis Sarkar towards developing the communication. 
International Journal of Social Science and Economic Research

ISSN: 2455-8834

Volume:05, Issue:08 "August 2020"

\section{REFERENCE}

[1]. Barclay, G. W. (1958). Techniques of Population Analysis. New York: John Wiley and Sons.

[2]. Bhende, A. and Kanitkar T., 2004, Principles of Population Studies, Himalaya Publishing House, Mumbai, pp. 158

[3]. Bose, A., Bose, P. B., \& Jain, S. P. (1970). Studies in Demography. London: George Allen and Unwin Ltd.

[4]. Chandna, R.C, 2005, Geography of Population: Concepts, Determinants and Patterns, Kalyani Publishers, New Delhi, pp. 300

[5]. Clarke, John I., 1972, Population Geography, Pergamon Press, Oxford. pp. 66

[6]. Dhillon P. and Ladusingh L., 2013, "Working life gain from gain in old age life expectancy in India", Demographic Research, Volume 28, Article 26, $5^{\text {th }}$ April, 2013, doi: 10.4054/DemRes.2013.28.26, pp. 734

[7]. East-West Population Institute, University Press of Hawaii, Honolulu, Hawaii.

[8]. Garnier, J. B. (1978). Geography of Population. London: Longman.

[9]. Government of India. (1961 - 2011). Census of India. New Delhi: Government of India.

[10]. Lutz Wolfgang, 2009, "The Demography of Future Global Population Aging: Indicators, Uncertainty and Educational Composition", Population and Development Review, Volume 35 , Issue $2,12^{\text {th }}$ June 2009 , pp. 1-6

[11]. Mandal, J. K. (2020) : Transformation of Age Sex Composition of Population of South 24 Parganas District, West Bengal, India,

[12]. Momsen, J. H., \& Townsend, J. G. (1987). Geography of Gender in the Third World. Hutchison: State University of New York Press.

[13]. Mukherjee Sudhansubhusan, 1976, The Age Distribution of the Indian Population : A reconstruction for the states and territories, 1881-1961,

[14]. Pressat Roland, 1978, Statistical Demography, Methuen \& Co Ltd, Cambridge, pp. 9

[15]. Schellenberg, J. R. M. A. and Berhanu D., 2020, "Major gaps in child survival by ethnic group", The Lancet, www.thelancet.com/lancetgh Volume 8, March 2020, pp. 1-2 
International Journal of Social Science and Economic Research

ISSN: 2455-8834

Volume:05, Issue:08 "August 2020"

[16]. Thomlinson R., 1965, Population Dynamics, New York: Random House, pp. 428

[17]. Trewartha, G.T., 1969, A geography of population: World patterns, John Wiley \& Sons, New York. pp. 122

[18]. United Nations, 1967, Principles and Recommendations for the 1970 Population Censuses, Statistical Papers, Series M. No. 44, pp. 41

[19]. International Journal of Humanities and Social Science Invention (IJHSSI), Vol-9 No-3, Pp 08-14

[20]. Saha, I and Sarkar, A (2015): Analysis of Age Sex Composition of Population of West Bengal, 1961 - 2011, Indian Journal of Spatial Science, Vol-6 No-1 Pp 1-9 